\title{
Enacting change through action learning: mobilizing and managing power and emotion
}

\author{
James Conklin ${ }^{1,2}$, Rochelle Cohen-Schneider ${ }^{3}$, Beth Linkewich ${ }^{4,5}$, Emma \\ Legault $^{1}$
}

${ }^{1}$ Department of Applied Human Sciences, Concordia University, Montreal, Canada

2 Bruyère Research Institute, Ottawa, Ontario, Canada.

${ }^{3}$ Aphasia Institute, Toronto, Ontario, Canada

${ }^{4}$ Sunnybrook Health Sciences Centre, Toronto, Ontario, Canada

${ }^{5}$ Northern Ontario School of Medicine, Thunder Bay, Ontario, Canada

Corresponding Author:

James Conklin

Concordia University

Department of Applied Human Sciences

Office L-VE-223

1455 de Maisonneuve Blvd. West

Montréal (Québec)

H3G $1 \mathrm{M} 8$

Email: jconklin@alcor.concordia.ca

\begin{abstract}
This paper reports on a study of how action learning facilitates the movement of knowledge between social contexts. The study involved a community organization that provides educational services related to aphasia and members of a complex continuing care (CCC) practice that received training from the agency. People with aphasia (a disability often caused by stroke) retain inherent cognitive competence but have difficulty communicating (speaking, writing, understanding). The agency has developed a communication technique that improves the ability of people with aphasia to communicate. This project used action learning to introduce a reflective learning cycle into two groups: the agency project team responsible for providing the training, and the $\mathrm{CCC}$ practice members who received the training. Research participants at both the agency and the CCC facility focused on issues of skill and capacity, and both groups credit the action learning process with introducing a helpful problem-solving cycle into the workplace. CCC participants found that the action learning set provided an emotional container for the anxieties experienced in their workplace. Agency participants found that they were able to use power differences as a way of bringing about beneficial changes.
\end{abstract}

Keywords: knowledge transfer, action learning, power, emotion

\section{Introduction}

This paper presents initial results from an exploration of the usefulness of

action learning as a small scale (and scalable) intervention into busy Canadian health care practices. Research has suggested that the frontlines of Canadian health care institutions are contending with a heavy workload and a near-frantic pace of work 
(Armstrong \& Daly, 2004; Ross et al., 2002a, 2002b). Politicians and policy makers have sponsored public consultations and policy reviews, and there have been earnest calls for a reorganization of health services, and new approaches to recruiting, educating, and deploying human resources within the country's health system (Romanow, 2002). Many suggest that change is imperative, and also that health workers and workplaces seem unusually resistant to change (Legare, 2009). At the same time, there is a growing demand for health services and treatments to be based on solid scientific evidence or well-established best practices, along with an acknowledgement that it often takes a long time to move new medical discoveries into frontline practice (Graham et al., 2006; Greenhalgh et al., 2004).

Our study considered whether action learning represents an effective way of introducing new ideas and practices into a health care workplace. Suppose members of a practice received two days of traditional classroom training in a technique that would bring benefits to their patients and that would strengthen their alignment with their overall philosophy of care; and suppose that after these practice members returned to their workplace they were organized into an action learning set that provided a problem-solving and learning environment for them as they attempted to implement the techniques they had just learned into their regular work routines. Might action learning promote the adoption and use of important new health care practices?

The study has produced some interesting findings concerning action learning and the movement of knowledge between social environments. In this article, however, we focus on findings related to the dynamics of emotion and power in the two action learning sets that we studied. We did not set out to generate new insights about emotion and power in action learning groups. However, emotion and power became prominent, though in different ways, in the two sets. 


\section{Background to the study}

This paper presents results from a research project focusing on the use of action learning sets to promote knowledge translation in Canadian health care practices. The research used two conceptual frameworks. The first was a social learning framework that sees problem-solving as a process of sensemaking and meaning making through the ongoing construction of coherence, purpose, identity, and competence (Conklin 2009, 2010a). The second was a knowledge transfer framework (Promoting Action on Research Implementation in Health Services, or PARIHS) that views knowledge transfer in terms of three dimensions: the knowledge itself, the organizational context receiving the knowledge, and the facilitation used to transfer the knowledge (Conklin \& Stolee, 2008; Kitson et al., 2008; Rycroft-Malone et al., 2002).

An existing educational intervention served as a natural laboratory for the research. This educational intervention was a two-day training program in a conversational technique designed to improve the interactions between caregivers and people with aphasia (PWAs). The research ethics protocol requires that the identity of the institution that developed and offers this program be treated as confidential, so this paper will refer to the institution as "the agency" and the training program as the Agency Conversational Technique (or ACT) program.

Aphasia is a language disability often caused by stroke. The approximately 100,000 Canadians living with aphasia retain inherent cognitive competence, but usually suffer a loss in relationships, roles and activities because aphasia interferes with the ability to express thoughts, read, write and understand what others are saying. PWAs find that when they try to discuss their health, they often cannot make themselves understood. Research shows that communicative participation for PWAs 
can be enhanced by providing skilled communication partners and communication resources (Kagan, 1995, 1998; Kagan et al., 2001).

The agency has developed a variety of programs and techniques that help PWAs to participate more fully in the conversations and social interactions that characterize a full and meaningful life. One of these programs is the two-day ACT training program. Through this training, caregivers are taught how to use conversational aids such as pictures, pen and paper, and whiteboards to provide the PWA with a variety of options and cues that help them to express their meaning. Using ACT, a conversation with a PWA might take more time than a conversation between two communicatively adept people, but ACT significantly improves the exchange of information. The training includes a focus on attitudes toward PWAs, a review of basic skills and techniques, and then several hours of hands-on practice with PWAs who volunteer to participate in the training.

When the research project began, the agency was entering the third year of an initiative to provide ACT training to caregivers within a specific geographic area in Ontario. During this third year, the agency team intensified the intervention by delivering the program to intact complex continuing care (CCC) teams, and by using action learning as a facilitation technique. Two action learning sets were established. One set consisted of members of the agency project team, and the second consisted of members of the frontline CCC practice that received the ACT training and attempted to implement the techniques in their daily work routines. The agency and their partners invited the article's first author to use this project as a natural laboratory for exploring the dynamics of knowledge translation. 


\section{Methods}

The research used ethnographic and case study methods that allowed a direct encounter with the phenomenon being studied, and the creation of a "thick description" of the phenomenon (Creswell, 1998; Denzin \& Lincoln, 2003; Fetterman, 1998; Hammersley \& Atkinson, 1995; Hopson, 2002; Lincoln \& Guba, 1985; Merriam, 1988). Ethics approval for the research protocol was received from the Research Ethics Boards at Concordia University and at the hospital that housed the participating CCC practice. The CCC team received the ACT training in March 2011, and approximately one month after this the two action learning sets were formed. The agency set consisted of the four members of the ACT team (three speech language pathologists who were responsible for training content and delivery, and one research assistant who handled project coordination and logistics), and the CCC set consisted of eight members of the institution's interprofessional care team (four nurses, one social worker, one occupational therapist, one speech language pathologist, and one recreation therapist). The agency set reflected on issues and concerns related to the ACT training program and their experience in encouraging trainees to make use of the techniques in their daily practice. The CCC set was encouraged to focus on specific issues that arose as they attempted to integrate ACT into their work routines. Both sets received an orientation to action learning, and then both sets held six meetings over a period of approximately three months. The meetings were facilitated by a graduate student who acted as a research assistant for the project (the fourth author of this article). In addition to facilitating the sets, she also made field notes to document the experience, and she created digital recordings of the set meetings (these were later transcribed). The research assistant also conducted interviews with each participant at the start of the action learning process, and close-out interviews at the end of the process. These interviews were also 
recorded and transcribed, and participants were given an opportunity to review and correct the interview transcripts.

The analytical strategy was based on Wolcott's conception of the analytical objectives of qualitative inquiry: to describe, analyze, interpret and explain the activities, people, places, and things involved in the case (Wolcott, 1994). Data was imported into NVivo and was coded using both directed and conventional coding techniques (Hsieh, 2005). This paper relies largely on the results of the directed coding that was performed on the interview data, and reports on barriers to action learning, the way participants experienced of the action learning process, the problems that were focused on, and the unexpected role that emotion and power played in the two sets. The full results of the project, which focused on action learning as a form of knowledge translation, will be reported on after the thematic analysis is complete.

\section{The Sequence of Events}

Participants for the two action learning sets were recruited from the agency project team and a CCC practice located in a large health care institution in the province of Ontario. Both sets were provided with an orientation to action learning, which included the establishment of "ground rules" for the set, after which the sets began work. All set meetings were attended by either the first or fourth author of this paper. For most meetings, the facilitator attended via a teleconference connection (in other words, the facilitator could hear, but could not see, the action learning participants). The researcher in attendance operated the digital recording device, and afterward wrote field notes about what had happened. The researcher also acted as a set facilitator, answering questions about the action learning process, occasionally suggesting a line of inquiry that might prove helpful, and reminding participants of 
the agenda that had been agreed to for the set meetings. In practice, the researchers rarely found it necessary to participate actively in the sessions, other than to help the group manage their time in relation to the agenda.

Each meeting would focus on two issues that participants felt were significant in their workplace. At the start of the meeting, the person who had acted as the focus of discussion in the previous meeting would report on actions taken in the intervening period, and results that were achieved. The group would ask questions to help this person make sense of these experiences and formulate a plan for additional actions. The meeting would then shift to a new issue that had been raised by another participant. Set members would help this person inquire into and reflect on the issue, and devise a strategy for taking action to better understand or resolve the issue.

The overall process in both action learning sets tended to involve the statement of an issue or problem related to the introduction of new knowledge into a frontline practice, an inquiry into the issue that generally resulted in a reframing that seemed less perplexing and more amenable to inquiry and improvement, and then a consideration of possible actions that could be taken in order to gain a better understanding of the situational constraints and affordances that characterized the issue, or that might bring about a change that could lead to improvements in the workplace or the improved wellbeing of PWAs being treated in the facility. This process bore a striking resemblance to the problem-solving process described by Donald Schön (1984) in his book, The reflective practitioner.

Both the agency team and the CCC team held six action learning sessions. Toward the end of the sixth session, both groups reflected on their experience in using action learning. A few months after the final session, the first author visited both sites 
to share preliminary findings, and to invite further reflection on the experience (these sessions were also used to generate additional data that was added to the dataset).

\section{Findings}

Patterns of learning within the two sites

Although the two action learning sets had somewhat different experiences that can be understood in terms of their different organizational contexts and the characteristics of set members, in broad terms both sets followed a similar course. Their initial discussions focused largely on making sense of the action learning process, and coming to terms with how action learning would work in their specific context. Once this basic level of comfort was achieved, the two sets began to work on specific workplace issues that were related to the transfer of ACT competencies from the agency to the $\mathrm{CCC}$ workplace. Although initially these issues seemed rather specific and technical—dealing with the details of meeting the objectives of the agency team, or applying ACT competencies in specific workplace interactionsbefore long both sets were delving into the contextual nuances that are characteristic of efforts to introduce new ideas and practices into busy workplaces.

The agency set considered the current organizational arrangements of their team, and the impact of certain competency gaps upon their ability to meet their objectives. They mapped these issues to the broader dynamics and priorities of the organization, and began to consider how they might intervene into and influence certain organizational practices in ways that would provide further support to the project while also benefitting the agency as a whole. They then shifted ground and began to consider the ways in which priorities were established for the agency, and the role and importance of innovation to the work of the agency. This led them to inquire into the very particular ways that expertise in the use of ACT might be observed and ultimately absorbed into the training curriculum. Toward the end of the 
action learning process, participants at the agency began to notice the impact that action learning was having on their own thinking and practice, and discussed ways in which reflective processes might be used to enhance the effectiveness of all teams and groups working within the agency.

The CCC action learning set began by focusing on specific issues related to their effort to integrate ACT into their day-to-day work routines. Quite naturally, their approach quickly became a matter of focusing on typical ways of interacting with specific residents (the organization had a norm of referring to clients as residents rather than patients) with aphasia or other communication disorders, and thus they found themselves attempting to contextualize their understanding of ACT. As different set members with different occupational backgrounds became the focus of the set's inquiry, it became apparent that they experienced three distinct scenarios in their efforts to use ACT. First, nurses described a multi-tasking work environment where they might have a quick exchange with an aphasic resident while providing daily care to several residents. The interaction would be one-to-one and would take place in the midst of a busy day, and some communication resources would be available. Second, most allied health workers described scheduled one-to-one interactions with residents that would often be of a longer duration, and where it might be possible to take the resident to a quiet location. However, the communication resources provided by the agency were generally not available to the allied health workers, but instead were sequestered in a manager's office. Third, the recreational therapist described a unique situation where she would be working with a group of residents, one of whom might have aphasia. In that case she would be facilitating a leisure activity and would want to include the aphasic resident in the activity, but would have to consider the needs of other residents and the flow of the 
activity. In this third scenario, the therapist also noted that she would need to consider whether the person with aphasia would want to be singled out as someone with special needs (for example, might the resident be embarrassed by seeming to cause a disruption in the flow of the activity).

As the CCC set continued and they delved into the contextual particularities of different residents and types of interaction, they came to focus on issues concerning the time and resources needed to create supportive social relationships with residents. At the same time, they noticed that the action learning process was acting as a forum in which they could support each other and develop a higher level of mutual understanding within their interprofessional team. In their final set meeting they focused on the broader issue of maintaining professional competencies, and how to sustain and share learning within a busy health care environment where many would only infrequently need to interact with people with aphasia.

Table 1 Summarizes the types of problems that became the focus of the two sets.

Table 1: The problems focused on by the two action learning sets

\begin{tabular}{l|l}
\hline $\begin{array}{l}\text { The agency action learning set } \\
\begin{array}{l}\text { Is there a more effective and sustainable way in } \\
\text { which we can approach the development of } \\
\text { pictographic resources (two meetings)? }\end{array}\end{array}$ & $\begin{array}{l}\text { Awareness and communication in relation to } \\
\text { efforts to implement new practices (two } \\
\text { meetings). }\end{array}$ \\
\hline $\begin{array}{l}\text { Innovation: observing skilled users of ACT as a way } \\
\text { of improving the method and the training (one } \\
\text { meeting). }\end{array}$ & $\begin{array}{l}\text { Time and resources to create social relationships } \\
\text { with residents (two meetings). }\end{array}$ \\
\hline $\begin{array}{l}\text { Innovation: what is it, and how can we (should } \\
\text { we?) be innovative at the agency (two meetings)? }\end{array}$ & $\begin{array}{l}\text { Maintaining competency-given the infrequency } \\
\text { when they can practice new skills, how can they } \\
\text { sustain their learning (two meetings). }\end{array}$ \\
\hline $\begin{array}{l}\text { How might a process like action learning benefit } \\
\text { the agency as a whole (one meeting)? }\end{array}$ & \\
\hline
\end{tabular}


In both action learning sets, then, there was a tendency to seek a more contextual understanding of the use of ACT competencies. Both sets spent time considering the constraints and barriers in their workplaces that could impede learning and innovation, and both discussed how their internal communication processes - in the agency set the question was posed in relation to the agency as a whole, while in the $\mathrm{CCC}$ set the question tended to focus on their interprofessional caregiving teammight be altered in ways that would bring improvement. Both sets considered a tension between existing priorities and the aspirations of team members, and both expressed a recognition of the importance of reflective processes for learning and change.

Many of these issues and impulses were commented on at length during the initial and closing interviews. For example, in all of the interviews participants were invited to talk about the barriers that they faced in their workplaces. The agency set members considered the barriers they encountered as they attempted to organize and deliver their ACT training programs. By the end of the action learning process, barriers related to the processes, people, and organizational factors within the agency were largely mitigated or resolved. As participants remarked:

I think we learned a good way to identify our problems and I hope we can continue to use those methods to problem solve and talk to and communicate within the team and I think it definitely helped us, the four of us within our team, but hopefully we can expand it to everyone who is involved in the project.

So I talked [at the start of the process] about the stresses of balancing the two positions, with my two different roles, as a barrier. For myself, it's easier [now] because a lot of the stuff has been taken from me and assigned to Betty. 
I think they've been barriers for a long time within our organization and I think it was really good, having Gwen there, as I said in the last meeting where she helped bring these problems to the executive level and ... it's comforting that they saw and heard us and actually did something about it almost right away.

The experience of barriers to learning and change was rather different in the CCC set. Over the course of the action learning process, participants arrived at a more nuanced understanding of the barriers that they faced, and also concluded that some barriers were not as insurmountable as they had once supposed. For example, using the ACT techniques can be rather time consuming, and CCC team members were initially concerned about how feasible it would be to use the techniques in the hectic hospital environment. However, through the action learning process they discovered that the benefits of using the techniques sometimes outweighed concerns about time. Moreover, they found that by communicating with an aphasic resident in ways that led to a more accurate understanding of the resident's needs, they sometimes saved time by avoiding having to follow-up with family members or carry out an unnecessary task. They also learned that the use of the ACT techniques was even more contextual than they had supposed. At times an aphasic resident might prefer not to be singled out and made the centre of attention. They also noted that having a close relationship with a resident, which allows you to understand the resident's preferences and quirks, is just as important as possessing a useful communication technique.

This development of a more nuanced understanding can also be seen in how participants described their expectations for the action learning sets in the preinterview, as opposed to how they described the actual experience in the postinterview. The agency team (see Table 2) initially hoped that the process would culminate in effective action and a deeper understanding of troubling issues. Not 
surprisingly, given the educational mandate of the organization, they were also curious about the action learning process itself. By the time the action learning process was complete, participants described the experience in a variety of ways. All participants stated that it was a positive experience, and speculated on how the process might continue to benefit the agency. They confirmed that a number of tangible results were achieved, and they also indicated that the process included moments of heightened emotionality.

Table 2: Expectations and experiences of action learning: the agency action learning set

\begin{tabular}{l|l}
\hline $\begin{array}{l}\text { What did you expect (pre interview) } \\
\begin{array}{l}\text { I expect to see the process lead to action and } \\
\text { change, both within the set and in the } \\
\text { organization. }\end{array}\end{array}$ & $\begin{array}{l}\text { What did you experience (post interview) } \\
\text { should integrate it into our work in the } \\
\text { agency and elsewhere. }\end{array}$ \\
\hline $\begin{array}{l}\text { I hope that the action learning set leads to } \\
\text { more effective dialogue and communication } \\
\text { that allows us to go deeper into the issues } \\
\text { that trouble us. }\end{array}$ & $\begin{array}{l}\text { The action learning set led to some useful, } \\
\text { tangible results. }\end{array}$ \\
\hline $\begin{array}{l}\text { I am curious about the action learning set } \\
\text { itself-about what is going to happen in our } \\
\text { set, and about the process of action learning. }\end{array}$ & Emotional highs and lows. \\
\hline & $\begin{array}{l}\text { Participating in this process made me feel } \\
\text { good in a variety of ways. }\end{array}$ \\
\hline & $\begin{array}{l}\text { I learned some important new things about } \\
\text { myself and about my colleagues. }\end{array}$ \\
\hline & $\begin{array}{l}\text { I now see reflection as a vital part of my } \\
\text { work, and I believe that it will lead to better } \\
\text { outcomes for the agency. }\end{array}$ \\
\hline
\end{tabular}

The CCC team also began with a straightforward set of expectations, and concluded the process with more nuanced reflections on the importance and impact of the process (see Table 3). Participants hoped that the process would serve a team building function, and the post-interviews suggest that this expectation was met. At the same time, however, several participants indicated that they were disappointed with the fact that some members attended set meetings only infrequently. Most said that they enjoyed the opportunity to reflect on workplace issues and to try out new behaviours within the framework of the action learning process. Several participants 
made strong statements about the importance of the action learning set as a place for receiving and providing emotional support:

I remember one of the sessions that [a social worker] was doing and it was a very difficult case where she needed to use her ACT technique to talk about very detailed information from the resident. I find that session was very supportive. We all are facing challenges in terms of lack of resources and the time but in terms of supporting each other, yes I know it is challenging but having the support from the team is very helpful in terms of encouraging [the social worker] or myself to communicate with patients. So it is very encouraging.

I think also reassuring your colleagues is valuable. ... I always think that's helpful even if it's a team member admitting that they don't know what to do, 'this resident gets frustrated with me and I don't feel like I can do it. Does anyone else feel that way or is it just me?' Because sometimes you need that forum to share. Yes, so reflecting on that, I think it was very helpful.

I think for the team to know that they're not alone. And regardless of what discipline you are, we are a team and we're here to support each other. We really do have a common goal although all of us are working on different aspects of the quality of life of a resident. In the end, we're all working with the same goal.

I was pleasantly surprised by how open everyone was to discuss their own areas of insecurity or difficulties, sometimes this can be tough in a group of other professionals to say, I'm really struggling with this, I'm not quite sure what to do. Myself included, ... and I found it was a really supportive environment to come forward and people weren't being at all judgmental ...

Table 3: Expectations and experiences of action learning: the CCC action learning set

\begin{tabular}{l|l}
\hline What did you expect (pre interview) & What did you experience (post interview) \\
\hline $\begin{array}{l}\text { I hope that action learning promotes mutual } \\
\text { understanding and team cohesion. }\end{array}$ & $\begin{array}{l}\text { The action learning set allowed me to get to } \\
\text { know and understand the perspectives of } \\
\text { the other members of the team. }\end{array}$ \\
\hline I hope that action learning will improve the & Action learning focused us on specific \\
\hline
\end{tabular}




\begin{tabular}{l|l}
\hline competency of staff & $\begin{array}{l}\text { people, problems and contexts, and this was } \\
\text { helpful. }\end{array}$ \\
\hline $\begin{array}{l}\text { I hope that people will participate and it will } \\
\text { help us to disseminate the techniques } \\
\text { throughout the institution }\end{array}$ & $\begin{array}{l}\text { The action learning set was a place where we } \\
\text { could receive emotional support and } \\
\text { encouragement from each other. }\end{array}$ \\
\hline I am embracing and enjoying the process. & $\begin{array}{l}\text { I was disappointed with the commitment, } \\
\text { participation, and level of collaboration of } \\
\text { some members of the action learning set. }\end{array}$ \\
\hline $\begin{array}{l}\text { The research project and the chance to } \\
\text { engage in reflection is useful. }\end{array}$ & I liked the time to reflect on our work \\
\hline I don't know what to expect. & $\begin{array}{l}\text { The action learning set was a good } \\
\text { experience, and it worked well. }\end{array}$ \\
\hline $\begin{array}{l}\text { I hope that we solve some of the problems } \\
\text { action learning sessions. }\end{array}$ & $\begin{array}{l}\text { The action learning set encouraged me to } \\
\text { practice the ACT techniques. }\end{array}$ \\
\hline & $\begin{array}{l}\text { We are incorporating elements from our } \\
\text { action learning set into other meetings and } \\
\text { practices in the institution. }\end{array}$ \\
\hline & $\begin{array}{l}\text { The action learning set went well, but I was } \\
\text { sorry to have to miss some of it. }\end{array}$ \\
\hline
\end{tabular}

\section{Emotion and power}

Both action learning sets focused on the emotionality of the experience, but in different ways. The agency set was made up of an intact project team, and there was an unequal power distribution among team members. One member was a director in the organization; a second was a valued external consultant; a third was a speech language pathologist in her first full-time job since graduating; and the fourth was an administrator who reported directly to the agency's president. The director was a member of the organization's executive team, and the others, in terms of the hierarchical organization of power, were in a subordinate position. This power differential became a significant issue that set members discussed at length in the first two meetings, and occasioned some worry and uncertainty. However, the set appeared 
to reach a satisfactory resolution of the power imbalance midway through its life, and all set members concluded that their success was due in no small measure to the presence of the director. The key, it seems, was their willingness to openly discuss the power differential and the discomfort it occasioned, and the way that the director comported herself within the set.

The following comments were made by members of the agency set at the start of the process:

I don't know that we actually talked about this but just a general note- it has an interesting - the whole different dynamics of the power differences but I do think it is important that you in your research note that there is that challenge and that it does - I think impact the group. Well, I think that it's okay for me. Just because in general I'm a pretty open and honest person and I don't usually have a problem expressing my concerns and stuff. I ... I just didn't expect it...it can just impact the openness because things get shared with bosses [laughs].

...it's quite interesting, the dynamic within the action learning set, just because Gwen is a director here, so she's one of the...big bosses. And, I know that [the first author] did not include [the Agency's president] in the action learning team, because of her position of power in the organization, and how that would affect the rest of the team... And I don't see a lot of difference in the dynamic between the rest of us and [the president] and Gwen.

Note the difference in these comments, made after the conclusion of the process:

I think it was really good...having Gwen there, as I said in the last meeting where they helped bring these problems to the executive level and it's good, it's comforting that they heard us and actually did something about it almost right away. I think they're organizational decision making problems... not problems, but say the pictographic thing. It's something that they have to decide at the executive level in 
order for anything to happen and so I think maybe it's a communication problem between the staff and the executive level and maybe that's why it didn't happen before. Maybe they didn't fully get the message or they didn't fully understand the problem. Or maybe it was just more... there's more clout coming from Gwen.

I think it [the action learning set] was really useful. I think it would have been different if Gwen wasn't a part of the group, because she is part of our executive team and a lot of our issues would really only be solved by the executive team so if it was like, other staff members, who aren't our bosses [laughs] on the team, I don't know if it would have been as useful or if it would have yielded as many actions, actual things that happened. So I think - I just think that it would have been very different if Gwen weren't on the team.

The agency's action learning set began by agreeing on a set of ground rules, and while discussing these rules they talked at length about the power imbalance in the group. The group decided that everything said during an action learning session should be kept confidential to the group. The director openly expressed her concern that this might occasionally present her with a double bind: to meet her commitment to the action learning set, she would need to keep information confidential; but to meet her commitment to the agency, she might need to share this same information with the executive team. She did not make assertive statements about her responsibility to exercise authority, but rather acknowledged the discomfort she was feeling. Ultimately the group agreed that while they would respect the confidentiality rule, it would be permissible for members to check with the set about whether matters discussed during a session could be communicated outside of the set. This was agreeable to all participants, and thus the group created a way of taking some issues to other parts of the organization for discussion and resolution. 
The emotionality in the CCC set was not occasioned by power imbalances, but rather was a reflection of an essential situational factor of this workplace. These caregivers provide health services to a vulnerable and needy population of residents. This calls for the creation of a supportive and helpful relationship between individual caregivers and residents, which can provoke anxiety in the caregivers as they work among this frail population. To cope with these emotional difficulties, it is necessary for members of the caregiving team to feel supported by their organization — by their leaders and colleagues. The action learning set became a place of respite and support from the anxiety and emotionality of working with vulnerable and needy people. For the agency set, emotionality was a symptom of a power imbalance that needed to be resolved; for the CCC set, emotionality was an inherent feature of the workplace that could be temporarily alleviated by the conversations and relationships available within the action learning set.

\section{Enacting organizational dynamics and dilemmas}

The experience of both of these action learning sets confirm the potential of action learning to allow for a thorough and deep exploration of organizational dilemmas. For example, consider the trajectory of conversation within the agency set. At the beginning of the process set members identified a number of problems that they wanted to discuss. Two participants focused largely on frustrations around the team's process to create pictographic resources. A second talked about the possibility of adjusting the ACT training to cover communication issues with people with dementia or Alzheimer's disease (over time, this evolved into a discussion of the freedom to contribute, revise, and innovate in relation to the training). A fourth participant talked about the way in which expert ACT users communicated with aphasic clients, and how this expertise might be captured and included in the 
curricula. As the sessions moved forward, however, participants recognized that the individual issues they were raising were all related to a deeper issue that concerned the need to maintain the quality of the ACT training, introduce new innovations into the training, and balance this work with the many competing priorities of the agency. One participant noted that their current approach to training "is good enough," and that they have a tendency to focus on today's emergencies and to ignore the need to innovate and improve. The fourth and fifth sessions focused on the agency's tendency to cope with urgent issues and emergencies, and to downplay the importance of staying current with new research and finding ways to continuously enhance the ACT techniques. The final meeting of the set was devoted entirely to a discussion of the action learning process, and how it might represent a way of allowing the agency's staff to see beyond today's urgent priorities and to see the long-term need to strengthen their programs and find new, innovative ways of impacting on frontline health care practices.

The action learning set was thus an enactment of the dynamics and dilemmas that characterize this workplace that allowed participants to arrive at a moment of shared insight and commitment (this mirroring of the organizational dynamic was also evident in the CCC set, and supports Vince's (2004) suggestion that an organization's dynamic can be re-enacted within an action learning set). Several participants commented that the experience was unusual for them in that they were unaccustomed to taking time to reflect and inquire together; their usual practice was to quickly devise and act on a proposed solution. Through the action learning process they were able to see that their immediate challenges were symptomatic of deeper, systemic issues, and that if they wanted to be released from their current treadmill of activity 
they would need to not simply solve problems but develop a greater problem-solving capacity.

Much the same thing happened in the CCC action learning set, where the original focus on specific residents and forms of interaction gave way to an appreciation of the action learning set as a holding environment for distraught caregivers. Kahn $(2001,2005)$ has noted that caregiving organizations must have the capacity to provide support for caregivers who routinely interact with people who are vulnerable and needy. In the context of Ontario's over-burdened health system, caregivers are run off their feet (CUPE, 2007). Although many professional licensing bodies require that practitioners engage in reflective activities as part of their continuous learning, in practice it is all but impossible to find the time to do so. Within the action learning set, members of this CCC interprofessional team rediscovered the emotional support of colleagues that makes this work possible.

At the end of the action learning process, both teams reflected on what had changed. Members of the agency set mentioned numerous changes, including greater job satisfaction, role clarity, a more balanced workload, and stronger relationships among team members. They also said that barriers to team effectiveness were identified and removed. They suggested that the set had devised a new method for identifying, analyzing, and resolving problems within this project team, as well as improved communication within the team, which might be expanded to others involved in the project and the agency. Participants also reported a sense of satisfaction and relief that the process had worked, that people proved themselves to be caring and trustworthy, and that the team had worked together to resolve the most serious problems. Power was a resource for the team, not an inhibitor; it was used to solve problems, not to punish. The action learning set also dealt with the subject of 
innovation (the factors that promoted and impeded innovation), which may make it easier to make the changes to the training needed for the coming year. A new graphic artist was hired, and the hiring process was devised by members of the action learning set (this was recognized as a significant achievement by set members). As one participant remarked, "I was surprised that it made such a difference, not that I didn't expect it to be helpful, but I didn't expect such dramatic changes to happen."

Members of the CCC action learning set reported that after completing the action learning process with its focus on integrating ACT into their practice, it was clear that ACT would indeed allow them to communicate more effectively with people with communication impairments like aphasia. This can be supported by several specific stories about using the techniques with residents. Participants also emphasized that the staff who received the training and who participated in the action learning set are using the techniques in their daily work, and they are also making the techniques more available to other staff in the institution. Interestingly, the full exploration of the ACT techniques through action learning also led these participants to conclude that although the ACT techniques are useful and important, they will always have to contend with a tension between effective and empowering communication with this population and the need to get their work done in a busy environment with residents who have complex and multiple health issues. In other words, the process left them with both a heightened appreciation for and competency in ACT, as well as a better understanding of how this innovation fits into their overall organizational context.

\section{Discussion}

This research project focused primarily on exploring the potential of action learning as a way of promoting knowledge translation in busy health care 
organizations. The research findings also offer some insights into power and emotion in action learning.

The agency set had to find a way of managing a significant hierarchical power differential. In practice, however, the group not only managed the power differential, but made it a useful resource in service of the group's goals. At the end of the process members were invited to reflect on why this power differential ended up being a strength rather than a liability for the group. Members suggest that the initial ground rules, particularly the rule concerning confidentiality within the group, was of vital importance, and they also point out that it quickly became evident that all members were respecting and following this rule. Moreover, the issue of power differences was openly discussed in the group. They brought it up in their first meeting, and continued to talk about it until it had become clear that all members of the group were comporting themselves appropriately. The director would openly state when she felt that her responsibility to the set and to the executive team were in conflict, and the group would then spend some time discussing how the situation might be handled. In a sense, the director took on the anxiety occasioned by conversations that were critical of existing organizational arrangements, and the rest of the team acknowledged and helped her to manage this anxiety (a process that seems consistent with the cycle of emotions that foster learning proposed by Vince and Martin (1993)). Before the halfway point of the action learning process, group members were coming to believe that power had become a resource rather than an impediment. When appropriate, the director acted as a conduit to the decision-making processes in the organization, and she was better able to explain the perspective of the team as a result of the thorough discussion of issues that took place during set meetings. Set members also indicated, however, that it would have been helpful for the full executive team to receive a 
briefing on the action learning process, so they could better understand the impetus for change that emanated from the set.

Perhaps one might characterize this success as involving a willingness to set aside what some have termed "power over" other people, and instead to focus on the "power to" pursue change and accomplishments and on an experience of gathering and using "power with" others (Berger, 2009; Fenwick, 2003; Woehrle, 1992). This is akin to Boulding's (1989) idea that coercive power can sometimes be a fragmenting force within social groups, while the power of integration — of relationships and mutual respect that promotes cohesion in human collectives - can enable negotiation, discussion, understanding, and care.

There was no hierarchical power imbalance in the CCC action learning set. Each participant was a member of the interprofessional caregiving team, and although there can be power differences along disciplinary lines, participants made no comments about the positive or negative impact of power on the group. However, just as power became a resource for the agency team, emotionality and emotional support came to play a key role in the CCC action learning set. Participants frequently described the frailty of their resident population, and the ambiguity that occurs when dealing with multiple health conditions. A stroke victim who suffers from aphasia might also be in the early stages of dementia, might experience hearing loss, and might also suffer from physical debilities that necessitate the use of a wheelchair. When caregivers attempt to communicate with these residents, motivated by a desire to empower them and to foster their inclusion in the activities of the facility, a resident might experience and express frustration. This results in an emotionally fraught environment that puts considerable strain on members of the interprofessional team. 
The action learning set became a useful tool for managing and releasing this emotionality. Simply by listening to each other, asking questions, expressing sympathy, and occasionally providing information about residents and their situations, team members experienced a sense of support and belonging. The action learning set's structure and process functioned as a container (Isaacs, 1999; Jaques, 1955; Smith \& Berg, 1997) or holding environment (Kahn, 2001, 2005) that provided emotional support for participants. Worries and concerns were validated, and the actions that emanated from this team became an expression of concern for the wellbeing of frail residents.

The full data set from this research project continues to be analyzed, and ultimately will yield a report that considers the usefulness of action learning as an approach to foster knowledge translation in Ontario's health system. In this preliminary report we can say that action learning produced moments of uncertainty and a sense of empowerment for both of these action learning sets. The power of reflective practice was affirmed, useful changes were devised and implemented, and relationships were strengthened.

\section{Conclusions}

Action learning has often been seen as a vehicle for social change and organizational development. Some have suggested that what is distinctive about change efforts informed by action learning is the focus on concrete issues grounded in the lived reality of participants, the bottom-up nature of the change, and the somewhat subversive character of the change effort (Edmonstone, 2011; Pedler, 2006). Some have noted that the power dynamics evident in some workplaces can present challenges for an action learning set (Rigg \& Trehan, 2008). Others suggest that for the change effort informed by action learning to have a lasting effect, there must be a 
meaningful connection between subordinates and managers that allows the learning to travel across hierarchical boundaries (Edmonstone \& Flanagan, 2007; Pedler, 2006; Watkins \& Marsick, 1993).

The study reported here provides support for these views, and shows how power might strengthen the learning process. In the agency, power became an explicit topic of conversation, and was framed as a resource to support the changes that emerged from the discussions. Participants in the agency attributed their success to the way that they were able to use power dynamics to their advantage, and most suggested that the director's sensitivity and transparency allowed them to make power an object for examination and testing.

Vince (2004) has pointed out that action learning can both reveal and mirror organizational dynamics. At the same time that organizational dynamics enable learning, they also impede learning (Conklin, 2010a, 2010b; Vince, 2002). When members of an action learning set pay attention to the dynamics occurring within the action learning set itself, viewing these patterns as representative of dilemmas in the larger social system (Linklater \& Kellner, 2008), they may begin to inquire into assumptions and fears that constrain both the set and the broader organization.

These views are consistent with the experience of the action learning set at the agency. After reaching agreement on how to handle the power dynamic evident in the set, members noticed that the director's double bind resembled other contradictory impulses that have come to characterize work at the agency. The need to experiment, conduct research, and produce useful innovations must be balanced against the need to meet the immediate (and sometimes urgent) requirements of a frail client population. Though this dilemma was not resolved, the reasons for its existence became clearer for participants. As the apparent ambiguity of confusing and 
conflicting priorities became more coherent, set members were able to focus on pragmatic issues that could alleviate some of the pressures that they had been experiencing. The experience of these participants suggests that by consciously naming the power imbalance and reflecting on how it might impact the process of learning, power became a resource for the group.

Action learning has been frequently linked to programs of learning, development and change within health care settings (Blackler \& Kennedy, 2004; Edmonstone, 2010; Revans, 1976). The encounter with an organization's power dynamic (as discussed above) can result in an action learning set attempting to discuss and understand "uncomfortable knowledge" (Vince, 2002), which can lead to an attempt to inquire into defensive routines that act as a constraint upon learning and change. Moreover, one distinctive feature of health care organizations is that many health practitioners work in close proximity to people who are sick, unhappy, and suffering, which can give rise to anxiety in the workers as they try to be helpful, and can also give rise to defensive mechanisms that protect the organization and its employees against this anxiety (Blackler \& Kennedy, 2002). When these uncomfortable situations arise, the ability of an action learning set to achieve its goals may depend on the extent to which the set can contain the discomfort and allow members to inquire into these difficulties (Vince, 2002).

This study reported in this paper provides additional support for these views, and offers the example of how two different sets were able to create a holding environment that allowed for inquiry into uncomfortable knowledge. At the agency, the key to achieving emotional safety lay in establishing ground rules that allowed for confidentiality, while also recognizing that this might occasionally place the director in a double bind. When the director experienced a double bind, she openly expressed 
this, and the group then worked together to help her manage the dilemma. The fact that she accepted and followed the requirement for confidentiality, and was honest and open about the difficulties that she occasionally experienced, created an atmosphere of trust and support within the group.

At the CCC facility, emotional safety was achieved through sympathetic listening to the worries experienced as caregivers attempted to integrate technical knowledge and skills with contextual knowledge of particular residents. Participants were surprised to learn that they encountered similar dilemmas and experienced similar reactions to these dilemmas. Interprofessional distinctions were mitigated as members of the caregiving team expressed sympathy and offered encouragement to each other. The two sets confirm the importance of building trust, of creating a sense of openness within the set, and of agreeing on a set of ground rules that participants can support.

The effort to introduce new scientific discoveries, innovations, and best practices into the frontlines of health care organizations continues to meet with mixed success. As Jonathan Lomas famously remarked, knowledge translation is a contact sport (CHSRF, 2006). The findings reported here remind us that this sport is played in complex, ambiguous social environments. Knowledge flows across social contexts most often through the medium of human relationships, where emotion and power are always in play.

James Conklin worked for 25 years as a consultant and manager in the fields of knowledge transfer and organization development. He currently teaches in the undergraduate and master's programs in the Department of Applied Human Sciences at Concordia University in Montreal, where is he an Assistant Professor. He is also an Associate Scientist at the Bruyere Research Institute in Ottawa, and is a Member Scholar of the International Institute for Qualitative Methodology. His research focus is on social learning and the role of knowledge transfer and exchange in efforts to bring about change to social systems. For four years he has led the formative and developmental evaluation of the Seniors Health Research Transfer Network in Ontario. James was elected a Fellow of the Society for Technical Communication in 2004. He has published articles and presented conference papers on topics in 
technical communication, social learning, and organizational and team effectiveness. He holds a PhD from Concordia University in Montreal.

Rochelle Cohen-Schneider, M.Ed reg. CASLPO,, is the Director of Clinical and Education Services at the Aphasia Institute in Toronto. Rochelle has practiced for more than thirty years as a SpeechLanguage Pathologist. She is interested in using models of Adult Education to understand how clinicians move from novice practitioners to experts. Through her work as a trainer/educator Rochelle is curious about how trainees take up and utilize new knowledge in their practice. Rochelle participated in the action learning set at the Aphasia Institute, which is reported on in this paper.

Beth Linkewich is an occupational therapist with experience across the continuum of stroke care in clinical, research, administrative, and academic settings. She completed her undergraduate work at Lakehead University in the areas of science and psychology, her OT training at the University of Toronto, and her Master's in Public Administration at Dalhousie University. Currently, she is working as the Regional Director of the North and East GTA Stroke Network at Sunnybrook Health Sciences Centre in Toronto. She is an Assistant Professor with the Northern Ontario School of Medicine and has worked in the Occupational Therapy Program at McMaster University. She is also an instructor with Ryerson University's G. Raymond Chang School of Continuing Education. She has training in interprofessional education and collaborative change leadership with the University of Toronto. Her areas of interest in research and collaboration include stroke and cognition, relation-centred care, interprofessional collaboration, system integration, and telehealth.

Emma Legault is a graduate student in the Master's program in Human Systems Intervention at the Department of Applied Human Sciences, Concordia University, Montreal. She acted as a Research Assistant for this project, and assisted with gathering and organizing of the data.

\section{References}

Armstrong, P. and Daly, T. (2004). There are not enough hands: Conditions in Ontario's long-term care facilities. Cupe Ontario. Downloaded on December 4, 2007 from http://cupe.ca/updir/Final_Report_Sept_04_CUPELTC-ReportEng2a.pdf

Berger, B.K. (2005): Power over, power with, and power to relations: Critical reflections on public relations, the dominant coalition, and activism. Journal of Public Relations Research, 17, 5-28.

Blackler, F., \& Kennedy, A. (2004). The design and evaluation of a leadership programme for experienced chief executives. Management Learning, 35, 181-203.

Boulding. K.E. (1989). Three faces of power. Newbury Park, CA: Sage.

CHSRF (Canadian Health Services Research Foundation). (2006). Bridging boundaries, creating knowledge: The power of good conversation. Final Report of Network Leadership Summits I and II. Retrieved from: http://28784.vws.magma.ca/knowledge_transfer/pdf/Bridging_boundaries_creating\% 20knowledge_final_e.pdf

Conklin, J. (2010a). Learning in the wild. Action Learning: Research and Practice, 7, 151-166.

Conklin, J. (2010b). Resisting change or preserving value: A case study of resistance to change in a health organization. International Journal of Knowledge, Culture and Change Management, 10, 481-493. 
Conklin, J., and Stolee, P. (2008). A Model for Evaluating Knowledge Exchange in a Network Context. Canadian Journal of Nursing Research, 40, 116-124.

Creswell, J. W. (1998). Qualitative inquiry and research design: Choosing among five traditions. Thousand Oaks, CA: Sage.

CUPE SCFP Ontario, (2007). Submission to the Standing Committee on Social Policy Re: An Act Respecting Long-term Care Homes; Bill 140. Downloaded on October 24, 2007, from www.cupe.on.ca/aux file.php?aux file $\mathrm{id}=26$

Denzin, N. K., and Lincoln, Y. S. (2003). "Introduction: The discipline and practice of qualitative research." In Eds. N. K. Denzin and Y. S. Lincoln, Collecting and Interpreting Qualitative Materials. Thousand Oaks: Sage Publications. 1-45.

Edmonstone, J. (2011). Action learning and organisation development: overlapping fields of practice. Action Learning: Research and Practice, 8, 93-102.

Edmonstone, J., \& Flanagan, H. (2007). A flexible friend: Action learning in the context of a multi-agency organisation development programme. Action Learning: Research and Practice, 4, 199-209.

Fenwick, T.J. (2003). Emancipatory potential of action learning: A critical analysis. Journal of Organizational Change Management, 16, 619-632.

Graham, I. D., Logan, J., Harrison, M. B., Straus, S. E., Tetroe, J., Caswell, W., and Robinson, N. (2006), Lost in Knowledge Translation: Time for a Map? The Journal of Continuing Education in the Health Professions, 26, 13-24.

Greenhalgh, T., Robert, G., MacFarlane, F., Bate, P., and Kyriakidou, O. (2004). Diffusion of innovations in service organizations: Systematic review and recommendations. The Milbank Quarterly, 82, 581-629.

Hammersley, M., and Atkinson, P. (1995). Ethnography: Principles in practice (Second edition). London: Routledge.

Hopson, R. K. (2002). Making (more) room at the evaluation table for ethnography: Contributions to the responsive constructivist generation. In K. E. Ryan and T. A. Schwandt (Eds.), Exploring Evaluator Role and Identity, (pp. 37-56). Greenwich, CT: Information Age Publishing.

Hsieh, H., \& Shannon, S.E. (2005). Three approaches to qualitative content analysis. Qualitative Health Research, 15, 1277-1288.

Isaacs, W. (1999). Dialogue: The art of thinking together. New York: Doubleday.

Jaques, E. (1955) Social systems as a defense against persecutory and depressive anxiety, in M. Klein, P. Heinmann, and R. E. Money-Kyrle (eds.) New Directions in Psychoanalysis, pp. 478-498. London: Tavistock Publications. 
Kagan, A. (1995). Revealing the competence of aphasic adults through conversation: A challenge to health professionals. Topics in Stroke Rehabilitation, 2(1), 15-28.

Kagan, A. (1998). Supported conversation for adults with aphasia: Methods and resources for training conversation partners." Aphasiology, 12(9), 816-830.

Kagan, A., Black, S., Duchan, J. F., Simmons Mackie, N., \& Square, P. (2001). Training volunteers as conversation partners using Supported conversation for adults with aphasia: A controlled trial. JSLHR, 44(3), 624-638.

Kahn, W. A. (2001). Holding environments at work. Journal of Applied Behavioral Science, 37, 260-279.

Kahn, W. A. (2005). Holding fast: The struggle to create resilient caregiving organizations. New York: Brunner-Routledge.

Kitson, A. L., Rycroft-Malone, J., Harvey, G., McCormack, B., Seers, K., and Titchen A. (2008). Evaluating the successful implementation of evidence into practice using the PARiHS framework: theoretical and practical challenges. Implementation Science, 3, 1 of 12 to 12 of 12 .

Legare, F. (2009). Assessing barriers and facilitators to knowledge use. In S. Strauss, J. Tetroe, \& I.D. Graham (Eds.), Knowledge translation in health care: Moving from evidence to practice (pp. 83-93). Oxford, UK: wiley-Blackwell.

Lincoln, Y.S., and Guba, E.G. (1985). Naturalistic Inquiry. Beverley Hills: Sage Publications.

Linklater, J. \& Kellner, K. (2008). Don't just do something ... stand there: using action learning to help organisations work with anxiety. Action Learning: Research and Practice, 5, 167-172.

Merriam, S. B. (1988). Case study research in education. San Francisco: JosseyBass.

Pedler, M. (2006). Editorial: Action learning for change? Action Learning: Research and Practice, 3, 1-4.

Pedler, M. (2005). Critical action learning. Action Learning: Research and Practice, 2, 1-6.

Rigg, C., \& Trehan, K. (2008). Critical reflection in the workplace: is it just too difficult? Journal of European Industrial Training, 32, 374-384.

Romanow, R. J. (2002). Building on Values: The Future of Health Care in Canada. Commission on the Future of Health Care in Canada. Downloaded on October 27, 2007, from: http://www.cbc.ca/healthcare/final_report.pdf

Ross, M.M., Carswell, A., and Dalziel, W. B. (2002a). Quality of workplace environments in long-term care facilities. Geriatrics Today, 5, 29-33. 
Ross, M.M., Carswell, A., and Dalziel, W. B. (2002b). Staff burnout in long-term care facilities. Geriatrics Today, 5, 132-135.

Rycroft-Malone, J., Kitson, A., Harvey, G., McCormack, B., Seers, K., Titchen A., and Estabrooks, C. (2002). Ingredients for change: Revisiting a conceptual framework. Quality and Safety in Health Care, 11, 174-180.

Schön, D.A. (1984). The reflective practitioner: How professionals think in action. New York: Basic Books.

Smith, K., and Berg, D. (1997) Cross-cultural groups at work, European Management Journal, 15(1), 8-15.

Vince, R. (2004). Action learning and organizational learning: Power, politics and emotion in organizations. Action Learning: Research and Practice, 1, 63-78.

Vince, R. (2002). The impact of emotion on organizational learning. Human Resource Development International, 5, 73-85.

Vince, R., \& Martin, L. (1993). Inside action learning: An exploration of the psychology and politics of the action learning model. Management Education and Development, 24, 205-215.

Watkins, K.E., \& Marsick, V.J. (1993). Sculpting the learning organization:

Consulting using action technologies. New Directions for Adult and Continuing Education, 58, 81-90.

Woehrle, L.M.. (1992). Social constructions of power and empowerment: Thoughts from feminist approaches to peace research and peace-making. Syracuse: Syracuse University Press.

Wolcott, H. F. (1994). Transforming qualitative data: Descriptions, analysis, and interpretation. Thousand Oaks, CA: Sage Publications. 